\title{
Bilateral orbital myositis and dacryoadenitis after sclerosing mediastinitis
}

\author{
Jason A Sokol ${ }^{1}$, Jamie Rosenberg ${ }^{2}$, Jeremy Clark ${ }^{* 3}$, William Nunery ${ }^{3}$, Hui Bae Lee ${ }^{3}$, Christian Wertenbaker ${ }^{2}$ \\ ${ }^{1}$ Oculofacial Plastic and Orbital Surgery, Kansas University Eye, Kansas University Medical Center, Kansas City, Kansas, USA \\ ${ }^{2}$ Department of Ophthalmology, Albert Einstein College of Medicine (AECOM)/ Montefiore Medical Center (MMC), Bronx, \\ New York, USA \\ ${ }^{3}$ Department of Ophthalmology and Visual Sciences, University of Louisville, Louisville, Kentucky, USA
}

Received: April 28, 2016

DOI: $10.5430 /$ crcp.v3n $4 p 33$
Accepted: June 26, $2016 \quad$ Online Published: July 12, 2016

URL: http://dx.doi.org/10.5430/crcp.v3n4p33

\begin{abstract}
A 49-year-old male with a history of sclerosing mediastinitis presented with complaints of bilateral (left greater than right) eye pain and redness for 3 weeks. Clinically, the patient demonstrated signs of bilateral dacryoadenitis and myositis. CT confirmed enlargement of both lacrimal glands and lateral rectus muscles. Due to the relationship between sclerosing mediastinitis and orbital inflammatory pseudotumor (OIP), the patient was treated with oral prednisone with a brisk response. OIP is common in ophthalmic practice and treating physicians should be aware of the associations with systemic disease processes.
\end{abstract}

Key Words: Orbital pseudotumor, Orbital myositis, Orbital dacryoadenitis, Sclerosing mediastinitis, Idiopathic orbital inflammation

\section{INTRODUCTION}

Orbital inflammatory pseudotumor (OIP), also known as idiopathic orbital inflammation (IOI), and sclerosing mediastinitis are idiopathic fibroinflammatory disorders. OIP is most usually a unilateral condition, but a few bilateral cases have appeared in the literature with a higher incidence in children. ${ }^{[1,2]}$ Sclerosing mediastinitis is a rare condition which causes dense fibrosis of the mediastinum. ${ }^{[3]}$ OIP presents with classic orbital signs and responds well to steroids. ${ }^{[4]}$ OIP and sclerosing mediastinitis have been described, however rarely, in prior patients (no change made because not relevant in the introduction, previous patients are discussed in discussion). ${ }^{[5]}$ We describe an adult patient with sclerosing mediastinitis who developed bilateral orbital inflammation.

\section{Case presentation}

A 49-year-old man with a history of diabetes mellitus and hypertension had recently been found to have a spinal mass after complaining of back pain (see Figure 1). After two non-diagnostic fine needle aspirations (non diagnostic indicates no malignant/inflammatory milieu was collected in the specimen - the FNA was completed to avoid open biopsy), a biopsy showed sclerosing mediastinitis (see Figure 2). He received $60 \mathrm{mg}$ of oral prednisone daily, and this was slowly tapered over 6 weeks. Two weeks after stopping the prednisone, he developed eye pain and redness. Visual acuity was $20 / 25$ in the right eye and 20/25 in the left eye. Confrontational visual fields were full and pupillary examination was normal. His left eye had mild restriction of ab-

*Correspondence: Jeremy Clark, MD; Email: docclark83@gmail.com; Address: 301 E Muhammad Ali Blvd, Louisville KY 40202, USA. 
duction. The conjunctiva was mildly injected (injection is a common ophthalmic term meaning redness/erythema of the conjunctiva/ocular adnexal tissues) bilaterally with left lacrimal gland enlargement and injection. Severe lacrimal tenderness was present in both eyes. Hertel measurements were $21 \mathrm{~mm}$ in both eyes. The remainder of the ophthalmic examination was unremarkable. Laboratory studies showed a normal white count, normal serum electrolytes, normal TSH/free T4, and normal liver function tests. Further immunologic workup was negative for anti-nuclear antibody (ANA), C-ANCA, P-ANCA, Anti-SM and Anti-RNP. Testing of Lyme titer, ACE/Lysozyme, hepatitis, syphilis and IgG was within normal limits. CT scan demonstrated bilateral lacrimal gland enlargement, proptosis, and medial deviation and enlargement of the lateral rectus muscles, consistent with OIP (see Figure 3). The patient was started on $100 \mathrm{mg}$ of oral prednisone daily. He experienced improvement in his orbital signs and symptoms by the following morning. During chronic steroid therapy careful communication with his primary care physicians ensured his diabetes remained controlled. After steroids were tapered over five months, the patient had a mild recurrence of dacryoadenitis. Given the patient's recurrence of symptoms after steroid taper we offered a lacrimal gland biopsy to the patient. He declined this procedure, electing to try immunosuppression again, and was agreeable to biopsy if there were subsequent relapses. At that time he was restarted on Prednisone $60 \mathrm{mg}$ daily, with good response. This dose was tapered over a 4 month course. At 12 month follow up the patient had no evidence of dacryoadenitis and he reported no orbital pain.

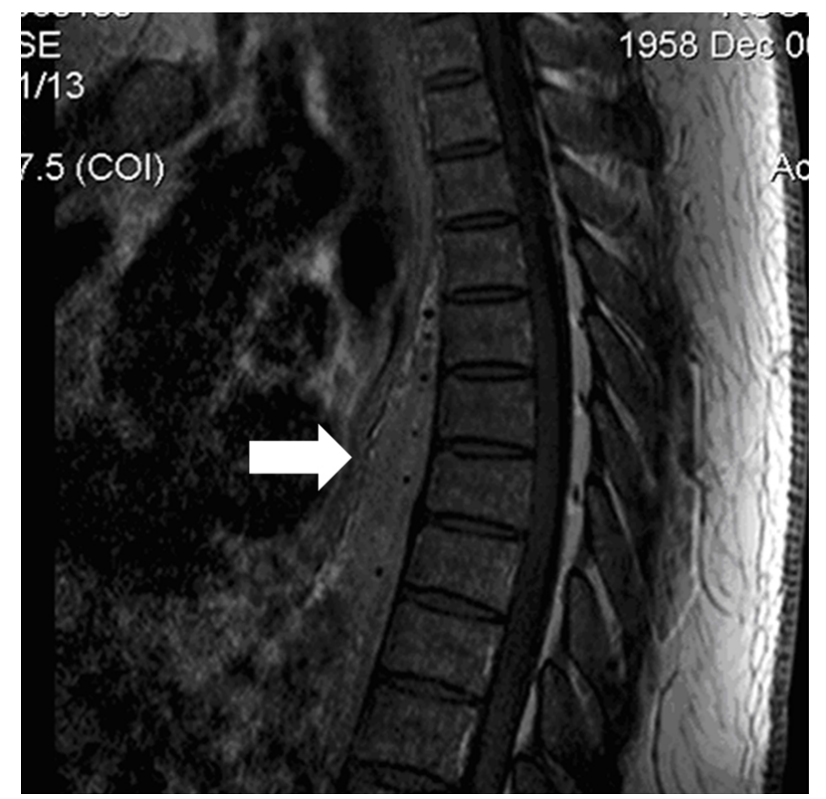

Figure 1. T1 Sagittal MRI of spine demonstrates a paraspinal mass extending from T4-5 to T10-11

\section{Discussion}

This case demonstrates the association of OIP with other idiopathic inflammatory conditions. Sclerosing mediastinitis is an indolent condition that usually presents in 40 to 60 years old patients. It is characterized by extensive fibrosis, with mild active inflammation, that may lead to invasion, compression or entrapment of mediastinal structures. It is usually idiopathic, but it can be related to sarcoidosis, silicosis, trauma, methysergide, histoplasmosis, tuberculosis, actinomycosis, aspergillosis, coccidioidomycosis, zygomycosis, nocardiosis, and lymphatic filiariasis. ${ }^{[6]}$

The diagnosis of sclerosing mediastinitis usually requires surgical biopsy. ${ }^{[6]}$ Steroids, immunosuppressive agents, and tamoxifen have been used to treat sclerosing mediastinitis. ${ }^{[7]}$ Some advocate surgical treatment. ${ }^{[6]}$

OIP is typically an IOI and is a diagnosis of exclusion, but can be associated with autoimmune diseases such as Wegener's granulomatosis, rheumatoid arthritis, and systemic lupus erythematosus; syphilis and infectious sinusitis have also been suggested as possible etiologic factors. ${ }^{[8]}$ There are reports that support an immunopathogenic basis for OIP, noting it's link to streptococcal pharyngitis, herpes varicella zoster, and Lyme Disease. ${ }^{[9-13]}$ OIP can present acutely or more insidiously, affecting any orbital tissue including fat, muscle, lacrimal gland, and optic nerve. Thyroid eye disease, sarcoidosis, orbital cellulitis, lymphoma and other orbital disease processes can often mimic OIP. ${ }^{[14]}$ OIP typically responds rapidly to steroid treatment, which aids in the diagnosis. However, due to the frequently relapsing course, some patients require alternative immunosuppressant drugs or radiotherapy. On the same note, rapid response to immunosuppresion should not be used to reliably diagnose OIP, and if recurrence occurs during or after steroid therapy, or if the disease course is unusual one should pursue biopsy. ${ }^{[14]}$

A connection between sclerosing mediastinitis and OIP has been described in the literature. Comings et al. described multifocal fibrosclerosis, including fibrosing mediastinitis, Riedel's thyroiditis, retroperitoneal fibrosis, sclerosing cholangitis, and pseudotumor of the orbit. ${ }^{[15]}$ They reported two brothers, with different combinations of multifocal fibrosclerosis. One had recurrent episcleritis, fibrosclerosis of the cystic duct, retroperitoneal fibrosis, and OIP. The older brother presented with extensive mediastinal fibrosis that responded to steroids. Eight years later, he developed symptoms of OIP, Reidel's thyroiditis and fibrotic contractures of his fingers. The article suggests that this category of diseases may have a genetic basis. ${ }^{[15]}$

DuPont et al. reported a case of OIP and mediastinitis in a 31-year-old woman. ${ }^{[16]}$ She presented with OIP in the left 
eye that responded well to radiation. Six years later, she had right-sided proptosis, which resolved spontaneously. Eight years after that she was found to have fibrous tissue through- out the mediastinum. She eventually required tracheotomy because of severe stenosis below the cricoid cartilage.
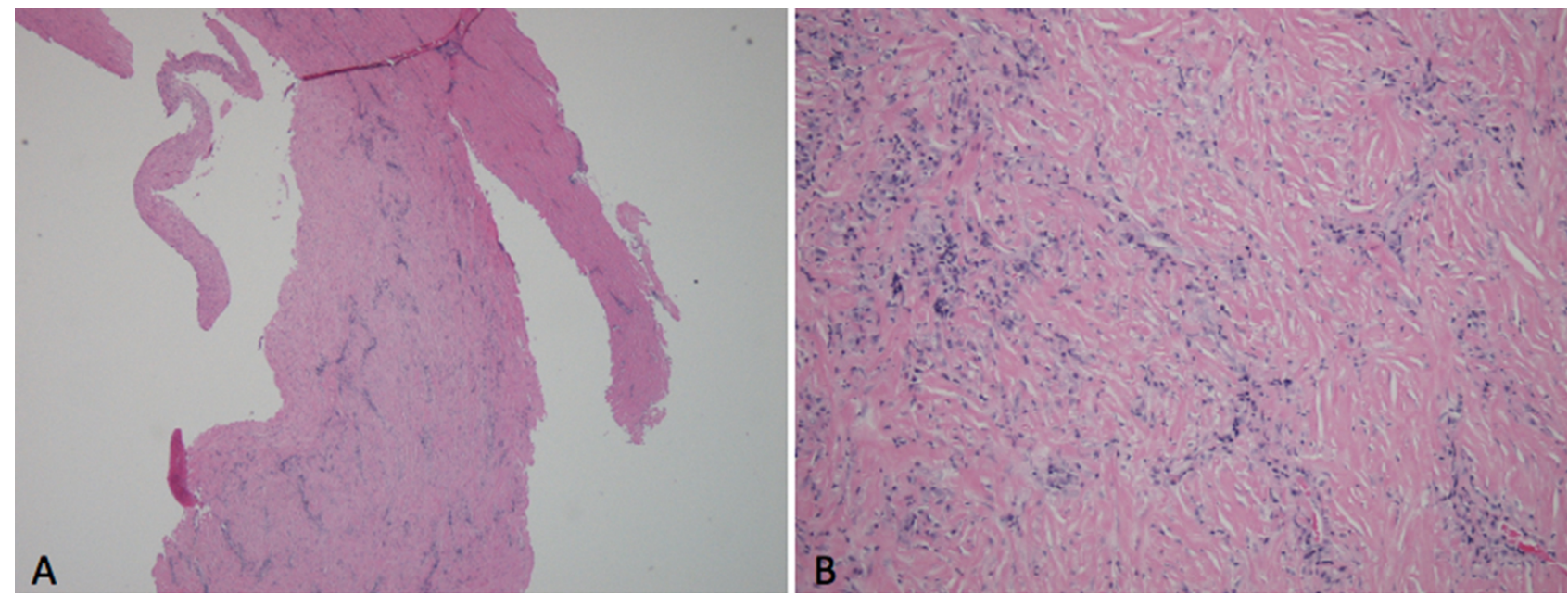

Figure 2. A. Low Power View (H and E) of biopsy specimen consists of membranous fragments of dense collagen tissue with marked chronic inflammation and sparse blend spindle cells that are immunohistochemically positive for smooth muscle actin, focally positive for cytokeratin (CAM5.2) and negative for desmin, S-100 and CD34, consistent with myofibroblasts. (Immuno-images could not be tracked down for inclusion in the manuscript) B. High Power View (H and E) further demonstrating showing chronic inflammation and spindle cells.
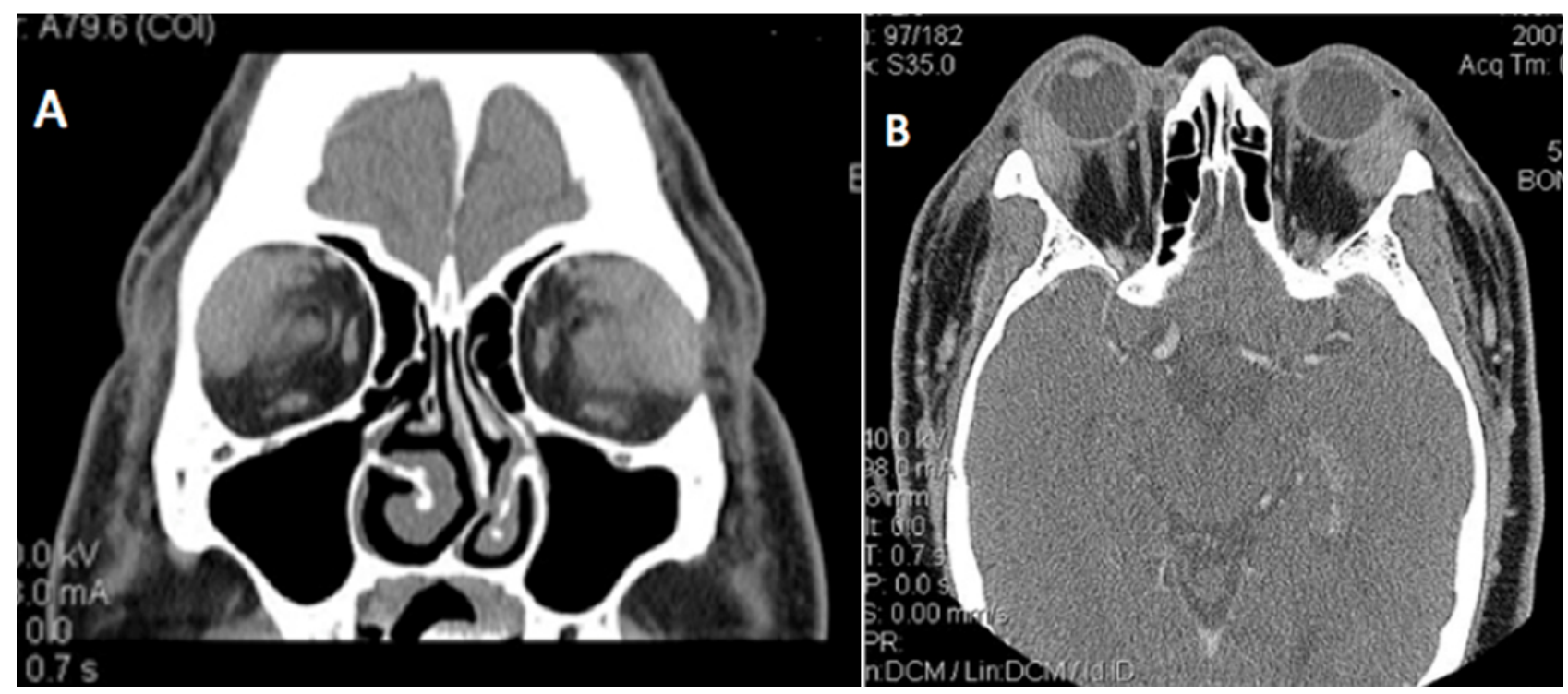

Figure 3. CT scan of maxillofacial bones demonstrates bilateral lacrimal gland enlargement, proptosis, and medial deviation and enlargement of the lateral rectus muscles, consistent with OIP. A. Coronal Section; B. Axial Image.

Sclerosing inflammatory disease of the orbit and abdomen were shown to have histologic similarities by Levine et al. in a 56-year-old white male who presented with OIP and a retroperitoneal mass. ${ }^{[17]}$

More recently reported cases have demonstrated IgG4related sclerosing disease associated with orbital pseudotu- mor and mediastinal fibrosis. ${ }^{[18,19]}$ IgG4 plasma cell staining on the paraspinal mass was not obtained and our workup during biopsy of the lacrimal gland would have included IgG4 staining, however our patient declined biopsy.

These cases describe multifocal fibrosclerosing syndromes that evolved over many years. Our patient's disease had a 
more rapid course. His presentation with a paraspinal mass was followed several months later by OIP which responded briskly to steroid treatment.

Since OIP is common in ophthalmic practice, it is important to be alert to the systemic manifestations of associated diseases.

\section{ACKNOWLEDGeMENTS}

This article was funded with support from Research to Prevent Blindness, New York, NY. All authors contributed equally to the collection and production of manuscript materials and data.

\section{CONFlicts OF INTEREST Disclosure}

The author declares no conflicts of interest.

\section{REFERENCES}

[1] Henderson JW, Farrow GM. Orbital tumors, 2nd edn. New York: Decker; 1984. 512p.

[2] Jakobiec FA, Jones IS. Orbital Inflammations. In: Jones IS, Jakobiec FA (eds) Disease of the orbit. Hagerstown: Harper and Row; 1979. $187 \mathrm{p}$.

[3] Mole TM, Glover J, Sheppard MN. Sclerosing mediastinitis: a report on 18 cases. Thorax. 1995; 50(3): 280-3. PMid: 7660343 http://dx.doi.org/10.1136/thx.50.3.280

[4] Swamy BN, McCluskey P, Nemet A, et al. Idiopathic orbital inflammatory syndrome: clinical features and treatment outcomes. Br J Ophthalmol. 2007; 91(12): 1667-70. PMid: 17620331. http: //dx.doi.org/10.1136/bjo.2007.124156

[5] Oguz KK, Kiratli H, Oguz O, et al. Multifocal fibrosclerosis: a new case report and review of the literature. Eur Radiol. 2002; 12(5): 1134-8. PMid: 11976858 . http://dx.doi.org/10.1007/s0033 0-001-1158-4

[6] Kang DW, Canzian M, Beyruti R, et al. Sclerosing mediastinitis in the differential diagnosis of mediastinal tumors. J Bras Pneumol. 2006; 32(1): 78-83. PMid: 17273573. http://dx.doi.org/10.1590/S 1806-37132006000100015

[7] Ikeda K, Nomori H, Mori T, et al. Successful steroid treatment for fibrosing mediastinitis and sclerosing cervicitis. Ann Thorac Surg 2007; 83(3): 1199-201. PMid: 17307498. http://dx.doi.org/1 $0.1016 / j$.athoracsur. 2006.09.034

[8] Mombaerts I, Goldschmeding R, Schlingemann RO, et al. What is orbital pseudotumor? Survey of Ophthalmology. 1996; 41: 66-78 http://dx.doi.org/10.1016/S0039-6257 (97)81996-0

[9] Venuta A, Frari P, Bevrelli A, et al. Acute post-streptococcal polymyalgia: two new cases with a review of the literature. Eur J Pediatr. 1995; 14: 475-6. http://dx.doi .org/10.1007/BF020 29359

[10] Nieto JC, Kim N, Lucarelli MJ. Dacryoadenitis and orbital myositis associated with lyme disease. Arch Ophthalmol. 2008; 126: 1165-6. PMid: 18695120. http://dx.doi.org/10.1001/archopht.12 6.8 .1165

[11] Kawasaki A, Borruat FX. An unusual presentation of herpes zoster ophthalmicus: orbital myositis preceding vesicular eruption. Am J
Ophthalmol. 2003; 136: 574-5. http://dx.doi.org/10.1016/S 0002-9394 (03) 00323-4

[12] Badilla J, Dolman P. Orbital myositis involving the oblique muscles associated with herpes zoster ophthalmicus. Ophthal Plast Reconstr Surg. 2007; 23: 411-3. PMid: 17881997. http://dx.doi.org/10. 1097/IOP. Ob013e318137a373

[13] Volpe NJ, Shore JW. Orbital myositis associated with herpes zoster. Arch Ophthalmol. 1991; 109: 471-2. PMid: 2012541. http://dx .doi.org/10.1001/archopht.1991.01080040039015

[14] Espinoza GM. Orbital inflammatory pseudotumors: etiology, differential diagnosis, and management. Curr Rheumatol Rep. 2010; 12: 443-7. PMid: 20803107. http://dx.doi.org/10.1007/s1192 6-010-0128-8

[15] Comings DE, Skubi KB, Van Eyes J, et al. Familial multifocal fibrosclerosis. Findings suggesting that retroperitoneal fibrosis, mediastinal fibrosis, sclerosing cholangitis, Riedel's thyroiditis, and pseudotumor of the orbit may be different manifestations of a single disease. Ann Intern Med. 1967; 66: 884-92. PMid: 6025229. http://dx.doi .org/10.7326/0003-4819-66-5-884

[16] DuPont HL, Varco RL, Winchell CP. Chronic fibrous mediastinitis simulating pulmonic stenosis, associated with inflammatory pseudotumor of the orbit. Am J Med. 1968; 44(3): 447-52. http: //dx.doi.org/10.1016/0002-9343(68)90115-0

[17] Levine MR, Kaye L, Mair S, et al. Multifocal fibrosclerosis. Report of a case of bilateral idiopathic sclerosing pseudotumor and retroperitoneal fibrosis. Arch Ophthalmol. 1993; 111: 841-3. PMid: 8512488. http://dx.doi.org/10.1001/archopht.1993.010 90060129037

[18] Cheuk W, Yuen HK, Chan ACL, et al. Ocular adnexal lymphoma associated with IgG4+ chronic sclerosing dacryoadenitis: a previously undescribed complication of IgG4-related sclerosing disease. Am J Surg Pathol. 2008; 32: 1159-67. PMid: 18580683. http://dx.doi.org/10.1097/PAS.0b013e31816148ad

[19] Tanabe T, Tsushima K, Yasuo M, et al. IgG4-associated multifocal systemic fibrosis complicating sclerosing sialadenitis, hypophysitis, and retroperitoneal fibrosis, but lacking pancreatic involvement. Intern Med. 2006; 45: 1243-7. PMid: 17139126. http: //dx.doi.org/10.2169/internalmedicine.45.1759 